\title{
Glucose metabolism outcomes in acromegaly patients on treatment with pasireotide-LAR or pasireotide-LAR plus Pegvisomant
}

\author{
Sabrina Chiloiro ${ }^{1,2}$ - Antonella Giampietro ${ }^{1,2} \cdot$ Felicia Visconti $^{1,2} \cdot$ Laura Rossi $^{1,2} \cdot$ Federico Donfrancesco $^{1,2}$. \\ Cara M. Fleseriu ${ }^{3,4}$. Federica Mirra ${ }^{1,2} \cdot$ Alfredo Pontecorvi $^{1,2} \cdot$ Andrea Giustina $^{5}$ - Maria Fleseriu ${ }^{3}$. \\ Laura De Marinis ${ }^{1,2} \cdot$ Antonio Bianchi $^{1,2}$
}

Received: 5 January 2021 / Accepted: 23 March 2021 / Published online: 27 April 2021

(c) The Author(s) 2021

\begin{abstract}
Introduction Disorders of glucose metabolism are a serious acromegaly comorbidity and may be differently impacted by medical treatments of acromegaly. In this retrospective longitudinal multicenter study, we investigated the outcome of glucose metabolism and its predictors in patients treated with Pasireotide LAR (PAS-LAR) alone or in combination with Pegvisomant (PAS-LAR + Peg-V).

Subjects and methods Acromegaly patients treated continously with PAS-LAR or PAS-LAR + Peg-V for at least 6 months. Results Forty patients (25 females, 15 males) were enrolled. At last visit, 27/40 patients $(67.5 \%)$ reached biochemical control of acromegaly. Overall, glucose metabolism improved in 3 (all in PAS-LAR + Peg-V; 7.5\%), worsened in 26 (65\%) and remained unchanged in 11 patients $(27.5 \%)$. Glucose metabolism worsened in 25 patients $(73.5 \%)$ treated with PASLAR and in a single patient $(16.7 \%)$ treated with PAS-LAR + Peg-V $(p<0.001)$. Among patients treated with Pas-LAR alone, $\mathrm{GH}$ at baseline was higher in those with worsening of glucose metabolism $(p=0.04)$ as compared to those with stable glucose status. A significantly higher reduction of HbAlc was observed in patients treated with PAS-LAR + Peg-V, as compared with those treated with PAS-LAR alone $(p=0.005)$.

Conclusions Our data confirmed that glucose metabolism in patients treated with PAS-LAR is often worsened, and may be predicted by entity of baseline GH hypersecretion and by the dose of PAS-LAR. Moreover, our data, although limited by small numbers, may suggest that the combination treatment PAS-LAR + Peg-V can improve glucose homeostasis in selected patients.
\end{abstract}

Keywords Diabetes $\cdot$ Glucose intolerance $\cdot$ Impaired fasting glucose $\cdot$ Impaired glucose tolerance $\cdot$ Somatostatin analogues $\cdot$ Growth hormone receptor antagonist

These authors contributed equally: Maria Fleseriu, Laura De Marinis

Laura De Marinis

laurademarinis@yahoo.it

1 Pituitary Unit, Department of Endocrinology and Diabetes, Fondazione Policlinico Universitario A. Gemelli, IRCCS, Rome, Italy

2 Dipartimento di Medicina e Chirurgia Traslazionale, Università Cattolica del Sacro Cuore, Rome, Italy

3 Pituitary Center, Oregon Health and Science University, Portland, OR, USA

4 University of Pittsburgh, Pittsburgh, PA, USA

5 Institute of Endocrie and Metabolic Sciences, Vita-Salute San Raffaele University and IRCCS San Raffaele Hospital, Milano, Italy

\section{Introduction}

Acromegaly is a systemic disease, caused by the hypersecretion of growth hormone $(\mathrm{GH})$ and type I insulin-like growth factor (IGF-I), that occur in almost all cases due to a pituitary tumor secreting GH [1]. The GH and IGF-I excess are responsible of several clinical disorders affecting multiple organ systems [2]. Diabetes mellitus and prediabetes are among the most frequent and clinically relevant comorbidities of acromegaly [3, 4].

Previous studies on glucose metabolism in acromegaly investigated the prevalence of diabetes mellitus, reported between 13 and $31.9 \%$ of cases [5-10]. Additional studies proved a prevalence of impaired fasting glucose (IFG) of $8.9 \%$ [10] and of impaired glucose tolerance (IGT) from $18.4 \%$ to $31.6 \%$ of cases $[5,7,10]$. Numerous 
studies have investigated the impact of different treatment regimens of acromegaly on glucose homeostasis [11-15]. However, no comparative studies have been performed and limited information on the predictors of glucose metabolism outcome with different acromegaly treatment are available. The aim of this study was to investigate the prevalence and predictors of glucose metabolism abnormalities after treatment with Pasireotide LAR (PAS- LAR) alone or in combination with Pegvisomant $(\mathrm{Peg}-\mathrm{V})$, in acromegaly patients, resistant or intolerant to first generation somatostatin receptor ligand (first gen-SRLs).

\section{Subjects and methods}

A longitudinal, observational, retrospective multicenter study was performed on consecutive acromegaly patient with acromegaly before (baseline) and after (end of study) treatment with PAS- LAR and PAS- LAR plus Peg-V.

All patients were enrolled according to the following inclusion and exclusion criteria.

\section{Inclusion criteria}

(1) Acromegaly patients treated with first gen-SRLs for at least 6 consecutive months and considered partial/ complete resistant or intolerant to SRLs [16, 17] at the study entry;

(2) patients on treatment with PAS- LAR and PAS- LAR plus Peg-V, for at least 6 months;

(3) patients older than 18 years;

\section{Exclusion criteria}

(1) Concomitant treatment with drugs known to influence glucose metabolism (as anti-psychotics, beta-blockers or thiazide diuretics), with the exception of glucocorticoid replacement therapy for central hypoadrenalism and anti-diabetic therapies for patients with glucose abnormalities at baseline;

\section{Study protocol}

Demografics and patients' clinical history were collected from records. Biochemical markers of acromegaly and glucose metabolism were collected both at baseline and at last evaluation visit (end of the study).

\section{Biochemical evaluation of acromegaly}

Resistance to conventional SRLs was defined [16, 17]:

partial: in case of a reduction of random GH and/or IGF-I $>50 \%$ with respect of pre-therapy values in absence of biochemical control of acromegaly disease and/or a reduction of tumor volume $>20 \%$;

complete: in case of a not-significant reduction of IGF-I and random GH value and/or of tumor volume.

At baseline, active acromegaly was diagnosed in patients with random GH higher than $1.0 \mathrm{ng} / \mathrm{mL}$ and IGF-I concentrations above the normal ranges for age [18]. During the study period, acromegaly patients were biochemically evaluated at least every 6 months, but variable depending on clinical status and Center's protocol. Acromegaly was defined controlled if normal age and gender IGF-I values and random GH was below $1.0 \mathrm{ng} / \mathrm{mL}$ [19]. Patients on treatment with Peg-V were evaluated only by serum IGF-I. A mean of all serum IGF-I values was calculated for each patient in order to have an integrated measure of evaluations of during the study period. IGF-I was expressed as IGF-I for upper limit of normal (ULN), according to normative data for each center laboratory. GH and IGF-I were measured in all centers using chemiluminescent immunometric assays (Immulite 2000, Siemens Healthcare, Erlangen, Germany). The standard for GH was IS 80/505 until 2010, IS 98/574 afterwards. The standard for IGF-I was IS 02/254. Coefficients of variation were below $5 \%$ for both assays.

\section{Glucose metabolism}

Data of glucose metabolism status were collected at baseline and at end of the study (last visit). According to medical history, fasting or after oral glucose tolerance test (OGTT) blood glucose and glycated hemoglobin (HbAlc) patients were classified as euglycemic, with IGT (impaired glucose tolerance)/IFG (impaired fasting glucose) or diabetes mellitus (DM) [20]. During follow-up, which was performed according to clinical practice, glucose evaluation was conducted every 3 or 6 months. At the end of the study (last visit), the glycometabolic status was defined:

improved, in case of reduction/withdrawal of anti-diabetic treatments or improvement of serum glucose paramentes; worsened, in case of increased dosage or new prescription of anti-diabetic treatments or worsening of serum glucose paramentes; unchanged, in case of manteinance of the same antidiabetic treatments or in case of not clinically significant variations of glucose parameters. 


\section{Ethical approval}

Registry databases were approved by institutional review boards of each institution and informed consent was waived for individual patients. All procedures performed in studies involving human participants were in accordance with the ethical standards and with the 1964 Helsinki declaration and its later amendments or comparable ethical standards.

\section{Statistical analysis}

All data were expressed as mean and standard deviation. Fisher exact and Student $t$ tests were used to compare categorical and quantitative un-paired data. A $P$ value $<$ 0.05 was considered statistically significant.

\section{Results}

A total of 40 patients, 25 females $(62.5 \%)$ were analyzed. Mean age at study entry was 35.4 years (SD: 11.7). The first line treatment was pituitary surgery for 36 patients (90\%) and medical therapy with first generation SRLs for the remaining 4 patients (10\%). All 40 patients who entered the study had undergone previous therapy with first generation SRLs. At baseline, all patients had active acromegaly with partial resistence to first generation SRL in 11 cases (27.5\%) and complete resistant in the remaning 29 cases (72.5\%). Thirty-four patients were treated with Pasi- LAR alone (85\%) and 6 patients with Pasi-LAR plus Peg$\mathrm{V}(15 \%)$.

At baseline, the glucose metabolism was considered normal in 18 patients (45\%), $13(32.5 \%)$ were affected by IGT/IFG and 9 patients (22.5\%) by DM. Eleven patients (27.5\%) were diet-controlled, 3 patients $(7.5 \%)$ treated with oral hypoglycemic drugs and 6 patients (15\%) with insulin. The remaining 20 patients were not treated for glucose abnormalities (50\%).

The baseline clinical features of the two treatment groups are summarized in Table 1.

At the end of the study, 27 patients $(67.5 \%)$ reached biochemical control of acromegaly. Glucose metabolism improved in 3 (7.5\%), worsened in $26(65 \%)$ and remained unchanged in 11 patients $(27.5 \%)$. In particular, 6 patients were considered euglycemic (15\%); 20 patients $(50 \%)$ had IGT/IFG and 14 patients (35\%) DM. Eleven patients $(27.5 \%)$ were on treatment with low calorie low glycemic index diet, 14 patients (35\%) with oral hypoglycemic drugs and 9 patients $(22.5 \%)$ with insulin. The remaining 6 patients did not follow specific therapeutic indications $(15 \%)$. The clinical features of the two treatment groups are summarized in Table 1.
Table 1 Study population features stratified for acromegaly treatments

Pasireotide LAR Pasireotide LAR $p$ value plus Peg-V

\begin{tabular}{|c|c|c|c|}
\hline $\begin{array}{l}\text { Number of } \\
\text { patients (\%) }\end{array}$ & $34(85 \%)$ & $6(15 \%)$ & \\
\hline \multicolumn{4}{|l|}{ Gender } \\
\hline Female n, $(\%)$ & $21(61.8 \%)$ & $4(66.7 \%)$ & 0.6 \\
\hline Male $n,(\%)$ & $13(38.2 \%)$ & $2(33.3 \%)$ & \\
\hline Mean age (SD) & $34.7(11)$ & $39.5(15)$ & 0.36 \\
\hline $\begin{array}{l}\text { Mean BMI at } \\
\text { baseline (SD) }\end{array}$ & $24.2(12.9)$ & $25.2(12)$ & 0.948 \\
\hline $\begin{array}{l}\text { Mean fasting } \\
\text { glucose (SD) }\end{array}$ & $109(30)$ & $122(40)$ & 0.361 \\
\hline Mean Hba1C (SD) & $5.9(0.8)$ & $7.5(1.6)$ & 0.518 \\
\hline $\begin{array}{l}\text { Mean IGF-I at } \\
\text { acromegaly } \\
\text { diagnosis (SD) }\end{array}$ & $3.3(1.2)$ & $4.8(2.4)$ & 0.01 \\
\hline $\begin{array}{l}\text { Mean GH at } \\
\text { acromegaly } \\
\text { diagnosis (SD) }\end{array}$ & $17(8)$ & $20(10)$ & 0.6 \\
\hline \multicolumn{4}{|l|}{ Invasion } \\
\hline Not-invasive & $11(32.4 \%)$ & 0 & 0.111 \\
\hline Cavernous sinus & $20(58.8 \%)$ & $2(33.3 \%)$ & \\
\hline $\begin{array}{l}\text { Cavernous sinus } \\
\text { plus other } \\
\text { structures* }\end{array}$ & $3(8.6 \%)$ & $4(66.7 \%)$ & \\
\hline \multicolumn{4}{|l|}{ GHR isoform } \\
\hline flf-carriers & $16(64 \%)$ & $3(60 \%)$ & 0.619 \\
\hline d3-carries & $9(36 \%)$ & $2(40 \%)$ & \\
\hline \multicolumn{4}{|l|}{$\mathrm{SSTR}^{\circ}$} \\
\hline Score 0-1 & $8(44.4 \%)$ & $3(75 \%)$ & 0.293 \\
\hline Score 2-3 & $10(55.6 \%)$ & $1(25 \%)$ & \\
\hline \multicolumn{4}{|l|}{ SSTR $^{\circ}$} \\
\hline Score 0-1 & $2(12.5 \%)$ & 0 & 0.632 \\
\hline Score 2-3 & $14(87.5 \%)$ & $4(100 \%)$ & \\
\hline Mean Ki-67 (SD) & $2.5(1.5)$ & $3.5(2)$ & 0.203 \\
\hline \multicolumn{4}{|c|}{ Resistance to first gen-SRLs } \\
\hline Partial n, (\%) & $11(32.5 \%)$ & 0 & 0.179 \\
\hline Complete $n,(\%)$ & $23(67.5 \%)$ & $6(100 \%)$ & \\
\hline $\begin{array}{l}\text { Mean IGF-I at } \\
\text { baseline (SD) }\end{array}$ & $3.1(1.9)$ & $3.3(1.7)$ & 0.993 \\
\hline $\begin{array}{l}\text { Mean GH at } \\
\text { baseline (SD) }\end{array}$ & $4(3)$ & $5(2)$ & 0.752 \\
\hline
\end{tabular}

Univariate analysis

\section{Glucose outcome and treatments}

\section{Pasireotide LAR}

At baseline, glucose metabolism was considered normal in 17 patients $(50 \%), 12(35.3 \%)$ had IGT/IFG and 5 patients $(14.7 \%)$ had DM. Nine patients $(26.5 \%)$ were diet-controlled, 2 patients (5.9\%) treated with oral hypoglycemic 

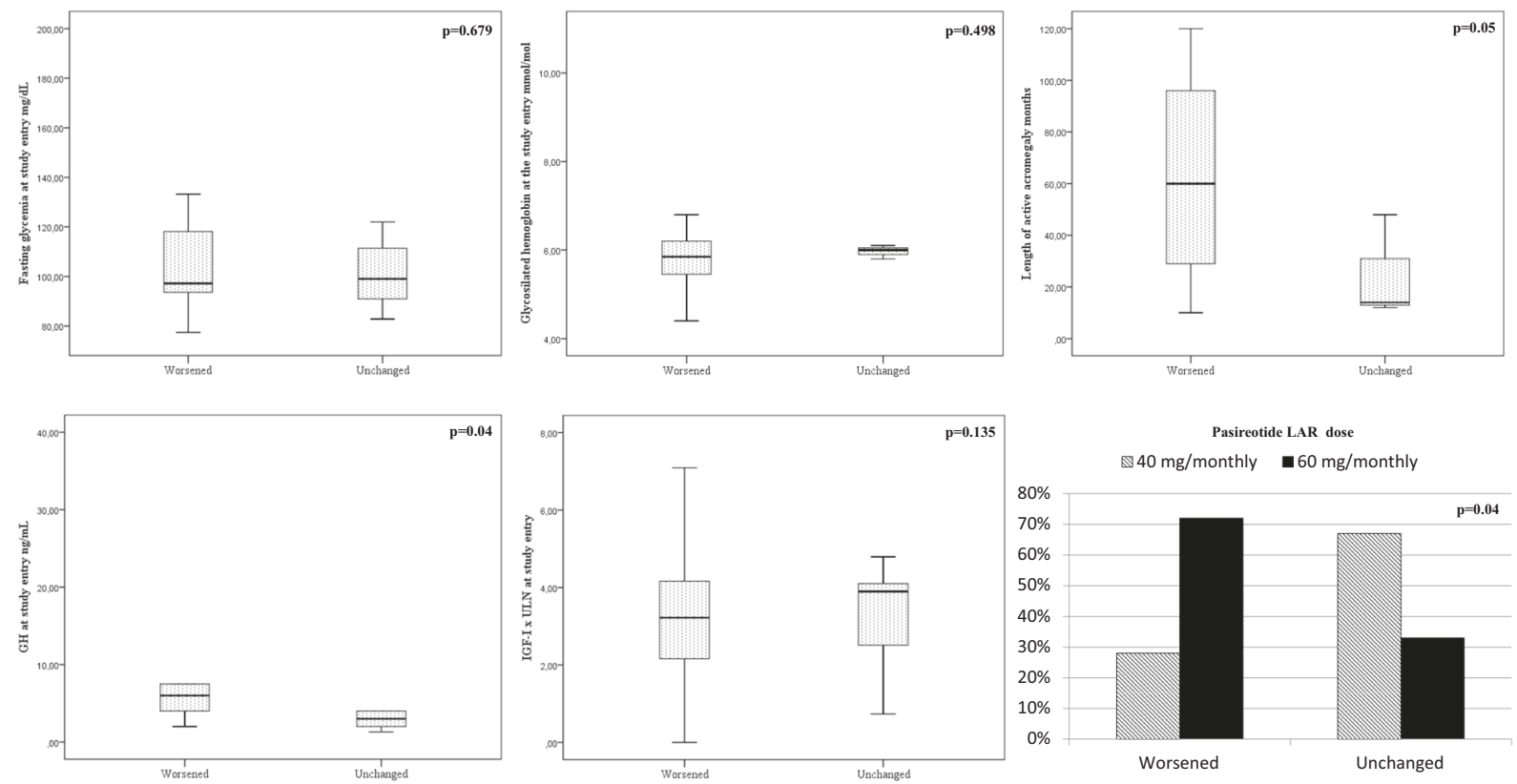

Fig. 1 Factors associated with glucose metabolism outcome in patients on treatment with Pasireotide LAR. Box plots. Univariate analysis

drugs and 4 patients $(11.8 \%)$ with insulin. The remaining 19 patients did not require treatments for glucose abnormalities $(55.9 \%)$ (Table 1). At the end of the study, glucose metabolism was unchanged in $9(26.5 \%)$ and worsened in 25 patients $(73.5 \%)$, at the end of the study.

In the PAS-LAR group, GH value at baseline was significatly higher $(p=0.04)$ in patients with worsening of glucose metabolism at the end of the study compared to patients with stable glucose status during the study period. No improvement of glucose metabolism was observed during PAS- LAR treatment (Fig. 1). Glucose metabolism outcome was similar among females and males $(p=0.6)$. Additionaly, we found that 12 of the 25 patients who experienced worsening of glucose metabolism had IGT/IFG or DM at baseline and the remaing 13 patients had normal glucose metabolism at baseline. Among these 13 patients, 5 patients were treated with oral hypoglicemic drugs and 2 patients with insulin (Table 2).

$\mathrm{HbA1c}$ was higher in the group of biochemically active patients on treatment with higher dose of PAS- LAR $(60 \mathrm{mg}$ monthly) then in those on treatment with $40 \mathrm{mg} / \mathrm{monthly}$, whereas the worsening in HbA1c was significantly greater with the higher dose in both patients with biochemically controlled and active acromegaly (Table 3 ).

\section{Pasireotide LAR plus Pegvisomant}

Six patients were on treatment with combination therapy with Peg-V and PAS- LAR. Before starting this combination therapy, a single patient was affected by IGT/IFG (16.7\%) and 4 patients by DM (66.4\%). At the end of the study, glucose metabolism was unchanged in $2(33.3 \%)$, worsened in a single patient $(16.7 \%)$ and improved in 3 cases $(50 \%)$. Therefore, combination treatment with PAS- LAR plus Peg-V was associated with a lower frequency of glucose metabolism worsening and with a higher frequency of glucose metabolism improving as compared to PAS- LAR alone $(p<0.001)$ (Fig. 2) and with a significantly reduction of $\mathrm{HbA} 1 \mathrm{c}$ during the treatment, $(p=0.005)$ (Fig. 3).

\section{Discussion}

Glucose homeostasis represents a relevant clinical problem in acromegaly, to which both GH and IGF-I hypersecrection and medical therapies can contribute, although their reciprocal role is not yet completely cLARified [2, 11$15,21,22]$. Concerning the latter aspect, an increased awareness was raised by the PAS- LAR use, which was associated with higher diabetes risk [13-15].

In this study, we investigated the alterations of glucose metabolism in acromegaly patients before and during longterm treatment PAS- LAR alone and in combination with Peg-V.

Before starting treatment with PAS- LAR, $32.5 \%$ of patients had IGT/IFG and $22.5 \%$ had DM. These data are in line with previous epidemiological data and with the notion that conventional SRLs have only a marginal role in glucose homeostasis [23], as all the patients of this cohort were treated with conventional SRLs, before starting PAS- LAR. Instead, at the end of the study, the prevalence of IGT/IFG 
Table 2 Study population features stratified for acromegaly treatments
Pasireotide LAR Pasireotide LAR plus Peg-V $\quad p$-value

\begin{tabular}{lccc}
\hline Glycemic assessment at baseline & & \\
Normal glucose status $n,(\%)$ & $17(50 \%)$ & $1(16.7 \%)$ & 0.019 \\
IGT/IFG $n,(\%)$ & $12(35.3 \%)$ & $1(16.7 \%)$ & \\
Diabetes Mellitus $n,(\%)$ & $5(14.7 \%)$ & $4(66.4 \%)$ & 0.258 \\
Treatment for glycemic assessment at baseline & $19(55.9 \%)$ & $1(16.7 \%)$ \\
None $n,(\%)$ & $9(26.5 \%)$ & $2(18.2 \%)$ \\
Hypocaloric hypoglycemic diet $n,(\%)$ & $2(5.9 \%)$ & $1(16.7 \%)$ \\
Oral hypoglycemic drugs $n,(\%)$ & $4(11.8 \%)$ & $2(18.2 \%)$ \\
Insulin $n,(\%)$ & & \\
Glycemic assessment at the end of study & $5(14.7 \%)$ & $1(16.7 \%)$ \\
Normal glucose status $n,(\%)$ & $18(52.9 \%)$ & $2(33.3 \%)$ \\
IGT/IFG $n,(\%)$ & $11(32.4 \%)$ & $3(50 \%)$ \\
Diabetes Mellitus $n,(\%)$ & & \\
Treatment for glycemin control & $5(14.7 \%)$ & $1(16.7 \%)$ \\
None $n,(\%)$ & $9(26.5 \%)$ & $2(18.2 \%)$ \\
Hypocaloric hypoglycemic diet $n,(\%)$ & $13(38.2 \%)$ & $1(16.7 \%)$ \\
Oral hypoglycemic drugs $n,(\%)$ & $7(20.6 \%)$ & $2(18.2 \%)$ \\
Insulin $n,(\%)$ & & \\
Acromegaly at the end of study & $22(64.7 \%)$ & $5(83.3 \%)$ \\
Controlled $n,(\%)$ & $12(35.3 \%)$ & $1(16.7 \%)$ \\
Active $n,(\%)$ &
\end{tabular}

Univariate analysis

Table $3 \mathrm{HbA} 1 \mathrm{c}$ and $\Delta \mathrm{HbA} 1 \mathrm{c}$ at the end of the study according to Pasireotide LAR dose

\begin{tabular}{|c|c|c|c|c|c|c|c|}
\hline & $\begin{array}{l}\text { Acromegaly disease status, } \\
\text { number of patients }(\%)\end{array}$ & $\begin{array}{l}\text { Pasireotide Lar } \\
\text { monthly dose }\end{array}$ & $\begin{array}{l}\text { Pegvisomant } \\
\text { daily dose }\end{array}$ & $\mathrm{HbA1c}$ & $p$ value & $\Delta \mathrm{HbA} 1 \mathrm{c}$ & $p$ value \\
\hline \multirow{4}{*}{$\begin{array}{l}\text { Pasireotide Lar alone } \\
(34 \mathrm{pts})\end{array}$} & \multirow[t]{2}{*}{ Controlled, 22 pts $(64.7 \%)$} & $40 \mathrm{mg}, 9$ pts $(40.9 \%)$ & \multirow[t]{4}{*}{$\mathrm{Na}$} & $6.4(0.4)$ & \multirow[t]{2}{*}{0.08} & $0.4(0.2)$ & \multirow[t]{2}{*}{0.003} \\
\hline & & $60 \mathrm{mg}, 13$ pts $(59.1 \%)$ & & $7.1(1.3)$ & & $1.2(1.4)$ & \\
\hline & \multirow[t]{2}{*}{ Active, 12 pts $(35.3 \%)$} & $40 \mathrm{mg}, 4$ pts $(33.3 \%)$ & & $5.8(0.9)$ & \multirow[t]{2}{*}{0.04} & $0.2(0.2)$ & \multirow[t]{2}{*}{0.03} \\
\hline & & $60 \mathrm{mg}, 8$ pts $(66.7 \%)$ & & $7.4(2.8)$ & & $0.9(2)$ & \\
\hline \multirow{2}{*}{$\begin{array}{l}\text { Pasireotide Lar plus } \\
\text { Peg-V (6 pts) }\end{array}$} & Controlled, 5 pts $(83.3 \%)$ & $60 \mathrm{mg}, 5$ pts $(83.3 \%)$ & $20 \mathrm{mg}$ (SD: 5) & $7.6(1.5)$ & \multirow[t]{2}{*}{$\mathrm{Na}$} & $-0.3(1)$ & \multirow[t]{2}{*}{$\mathrm{Na}$} \\
\hline & Active, $1 \mathrm{pt}(16.7 \%)$ & $60 \mathrm{mg}, 1 \mathrm{pt}(16.7 \%)$ & $30 \mathrm{mg}$ & 5.8 & & 0.4 & \\
\hline
\end{tabular}

$\Delta \mathrm{HbA1c}$ was calculated as the difference of HbA1c collected at the end of the study and that collected at baseline

and DM increased, involving respectively the $50 \%$ and the $35 \%$ of cases. We found that the glucose status worsened in 25/34 on PAS-LAR $(73.5 \%)$ and in a single patient treated with Pasi- LAR plus Peg-V. Our data are in line with previous authors that reported hyperglycemia and new onset DM in around $57 \%$ and $20 \%$ of patients on treatment with PAS- LAR [13-15]. Interestingly, more than half of patients with worsened glusose metabolism had normal glycometabolic status before treatment although it was previously suggested a predictive role of pre-PAS LAR treament glucose parameters [24]. Conversely, we found that the higher PAS-LAR dose $(60 \mathrm{mg} / \mathrm{monthly})$ correlated significantly with glucose control worsening, in particular with the increase in HbA1c, both in active and controlled acromegaly, at the end of the study. Another original finding of our study is that the higher GH levels may predict the worsening of glucose metabolism during Pasi-LAR treatment. This finding was identified also in other co-morbidities of acromegaly as bone fragility [25-28]. GH and IGF-I induce several metabolic changes that are actually not completely clarified [29, 30]. GH acts with a bimodal effect on glucose homeostasis, stimulating beta-cell proliferation, insulin synthesis and secretion, but also increasing lipolysis, gluconeogenesis $[31,32]$ and inducing systemic insulin resistance in active acromegaly $[33,34]$. As a consequence, $\mathrm{GH}$ excess per se may induce IFG, IGT, and DMII [35, 36]. 
However, GH action is also mediated by IGF-I that is mostly synthesized in hepatocytes upon GH receptor binding [37]. Conversely, IGF-I has been shown to increase insulin sensitivity [29]. Deterioration of glucose metabolism in patients with higher GH and IG-I levels has also been observed in patients partially resistant to SRL treated with high octreotide dose [38].

Taken together, these findings suggest that the higher dose of PAS-LAR needed to control a more biochemically active disease may have contributed to a greater glucose metabolism alteration. In fact, it is already known that in the presence of a more active disease at baseline, it is more difficult to obtain biochemical control of acromegaly [39]. Moreover, PAS-LAR has been shown to decrease insulin secretion acting at pancreatic beta cell level and to also decrease GIP and GLP-1 secretion [24]. Therefore, based on our data it can be hypothesized that in our population a combined mechanism represented by negative direct

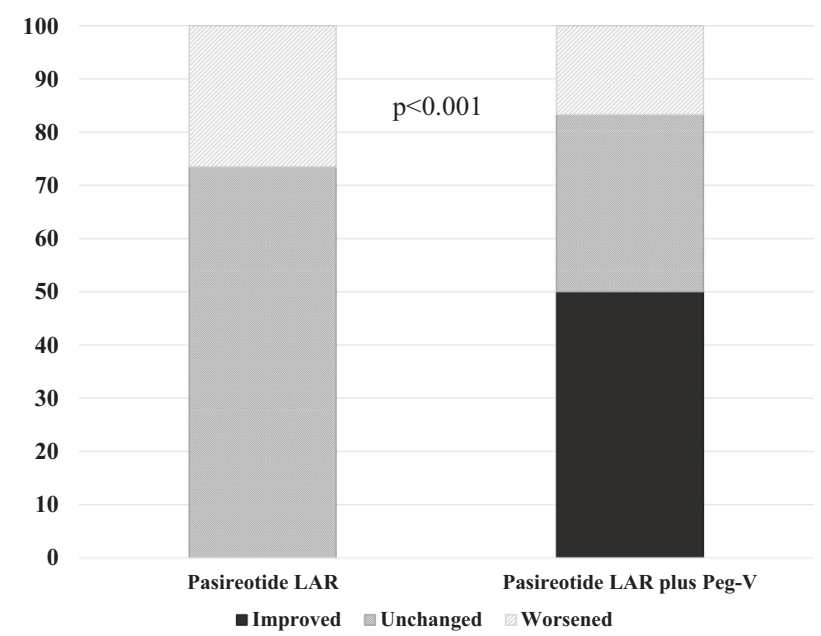

Fig. 2 Glucose outcome according to acromegaly treatments. Histogram. Univariate analysis pancreatic effect of PAS-LAR combined with detrimental effects of high GH on insulin resistance may occur [40] although our data did not allow to clarify which of the two mechanisms could be cliinically prevalent in determining the observed metaboslic worsening.

Finally, we found in the group of patients under Peg-V plus PAS- LAR the combination treatment may not only improve biochemical control but also mitigate the worsening of glucose metabolism caused by PAS- LAR alone. In fact, as shown in Fig. 4, all but one patients experienced a reduction of the $\mathrm{HbAlc}$. Interestingly, the reduction of pretreatment HbA1c was significantlly greater in patients treated with PAS-LAR in combination with Peg-V as compared to those of patients treated with PAS-LAR as monotherapy (Fig. 3). These results are different with those of Muhammad et al and could be explained by uptitrating doses of Peg-V in a clinical setting like ours vs a prospective design with fixed doses which aimed to spare Peg$\mathrm{V}$ dose. Furthermore, PAS- LAR dose in that study was $60 \mathrm{mg}$ monthly which we showed to have a worsening effect on glucose in our study.

This improvement of glucose metabolism can also be due to the biochemical efficacy of this combination therapy, that we recently described to be effective in a group of acromegaly patients affected by a disease resistant to multimodal treatments [41]. In fact, patients who required combination treatment PAS- LAR plus Peg-V had higher values of IGF-I at acromegaly diagnosis, if compared with cases treated with PAS- LAR alone. However, these IGF-I levels did not correlate with the glucose outcome $(p=$ 0.943). Alternatively, though not confirmed in Muhammad et al. [42], it may be suggested that Peg-V per se may have a protective effect on the hyperglycemic effect of PAS- LAR possibly reducing insulin resistance in some patients [43].

The significant limitations of this study are its retrospective design and the absence of randomization for the acromegaly treatment. Likewise, the small size of the group
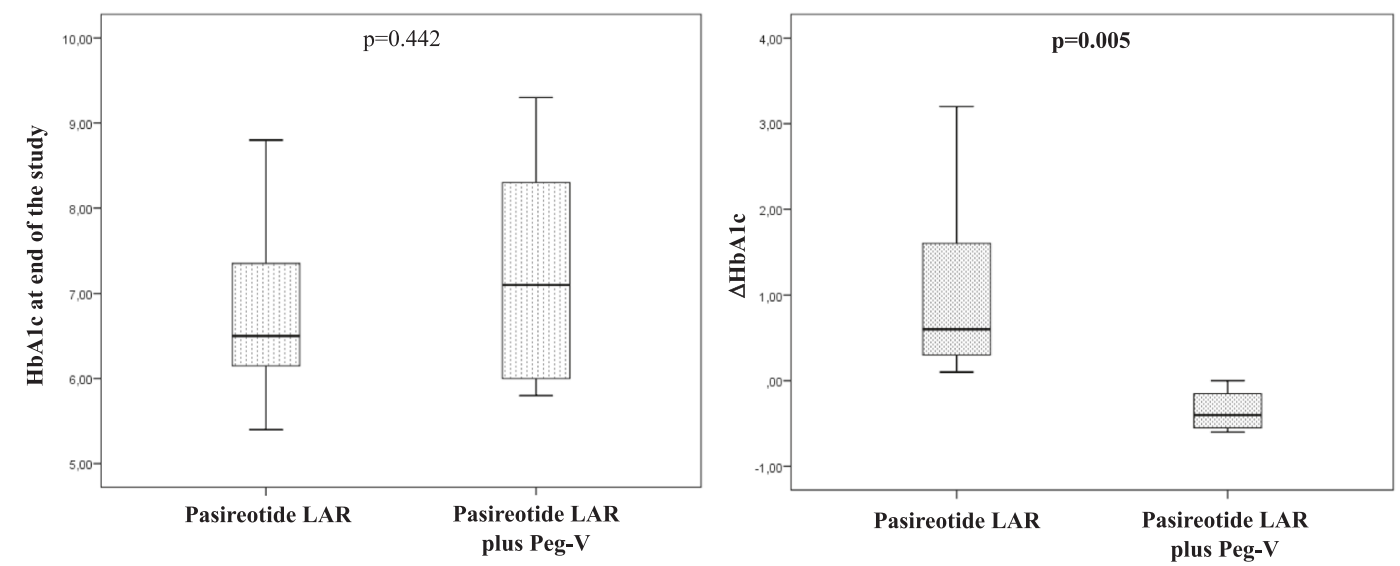

Fig. 3 Glicometabolic control at the end of the study according to treatments. Box plot. Univariate analysis 


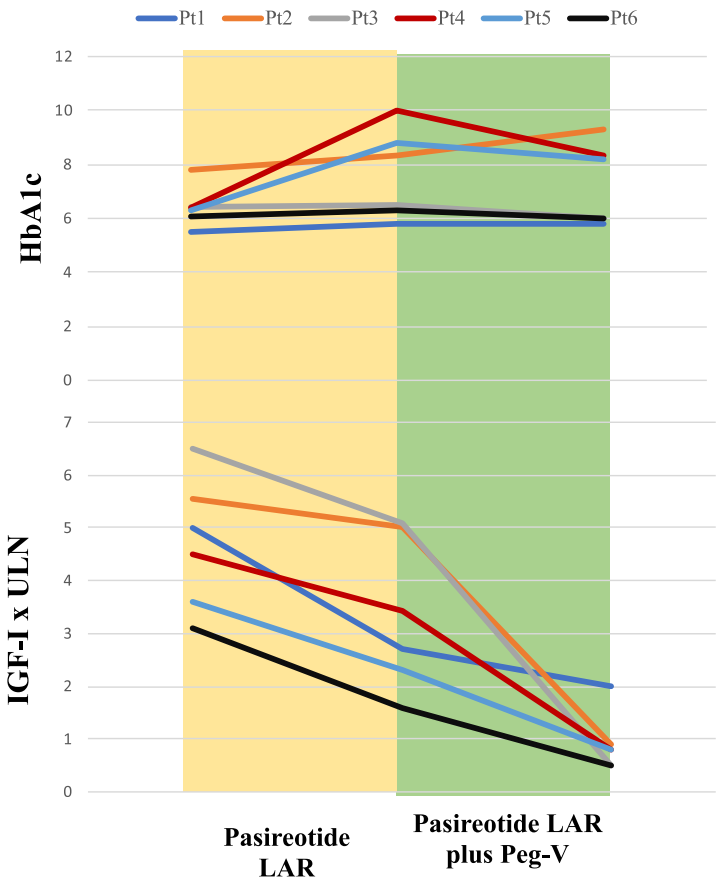

Fig. 4 Trend of HbAlc and IGF-I during treatment with Pasireotide LAR as monotherapy and in combination with Peg-V

of patients treated with PAS- LAR plus Peg-V reduced the power of comparative analysis. However, although the number of patients by us reported on treatment with PASLAR in combination with Peg-V is limited, experiences on glucose outcomes with this new form of therapy are scant and controversial [21, 38, 42, 44]. This combination is also currently included in consensus guidelines [21] for particularly resistant acromegaly, thus we think that this multicentric experience can be a useful addition to the available clinical evidence. In fact, based on our data it can be hypothesized that in patients in whom residual tumor and diabetes are both clinical concerns [45] and are not sufficiently controlled by first generation SRLs, a combination of PAS-LAR and Peg-V may be a viable option. In addition, the design of this study did not allow us to compare head to head Peg-V vs PAS-LAR in their effects on glucose metabolsim and did not provide any direct insights on the mechanisms underlying their effects.

In conclusion, we confirm previous data that glucose metabolism is often worsened during second line medical treatment with PAS-LAR in acromegaly. Our results suggest that this glucose worsening may be due to the use of PAS-LAR according to guidelines (45) in acromegaly patients with severe disease which in turn require high doses of the drug. In fact, both high GH levels per se as well as PAS-LAR may directly and potentially synergistically be detrimental for glucose metabolism. In this light, our data, although limited by small numbers, are among the first to suggest that the combination treatment PAS-LAR plus Peg-
V can not only improve biochemical control but also glucose homeostasis in selected patients. If confirmed in larger studies, this combination could be suggested earlier in the treatment of patients with resistant acromegaly and concomitant abnormalities in glucose metabolism.

Author contributions CS designed the study and draft the article. G.A., V.F., R.L., F.D., C.M.F., M.F. acquired the data. G.A., D.L., M.F., C.M.F., B.A. draft the article and revised it critically for important intellectual content. All authors approved the final version to be submitted.

Funding Open access funding provided by Università Cattolica del Sacro Cuore within the CRUI-CARE Agreement.

\section{Compliance with ethical standards}

Conflict of interest MF reports serving as an investigator with research grants to OHSU for Crinetics, Chiasma, Ionis, Novartis, Recordati; and serving as an occasional consultant to Crinetics, Chiasma, Ipsen, Novartis, Pfizer, Recordati. ORCID: 0000-0001-9284-6289, AG: Research Grants from Ipsen, Novartis and Pfizer. Consultant for Genevant and Ipsen. The other authors have nothing to disclose.

Ethical approval (Institutional Review Board approval was received).

Consent to participate (a waiver of subject consent was approved).

Consent for publication (all authors approve the submission).

Publisher's note Springer Nature remains neutral with regard to jurisdictional claims in published maps and institutional affiliations.

Open Access This article is licensed under a Creative Commons Attribution 4.0 International License, which permits use, sharing, adaptation, distribution and reproduction in any medium or format, as long as you give appropriate credit to the original author(s) and the source, provide a link to the Creative Commons license, and indicate if changes were made. The images or other third party material in this article are included in the article's Creative Commons license, unless indicated otherwise in a credit line to the material. If material is not included in the article's Creative Commons license and your intended use is not permitted by statutory regulation or exceeds the permitted use, you will need to obtain permission directly from the copyright holder. To view a copy of this license, visit http://creativecommons. org/licenses/by/4.0/.

\section{References}

1. Melmed, S. Pituitary-tumor endocrinopathies. N Engl J Med. (2020). https://doi.org/10.1056/NEJMra1810772

2. Gadelha, M.R., Kasuki, L., Lim, D.S.T., Fleseriu M. Systemic complications of acromegaly and the impact of the current treatment landscape: an update. Endocr Rev. (2019). https://doi.org/10. 1210/er.2018-00115

3. D. Solari, R. Pivonello, C. Caggiano, E. Guadagno, C. Chiaramonte, G. Miccoli, L.M. Cavallo, M. Del Basso De Caro, A. Colao, P. Cappabianca, Pituitary adenomas: what are the key features? what are the current treatments? where is the future taking us? World Neurosurg. 127, 695-709 (2019) 
4. S.Ç. Altuntaş, M. Evran, M. Sert, T. Tetiker, Markers of metabolic syndrome in patients with pituitary adenoma: a case series of 303 patients. Horm Metab Res. 51, 709-13 (2019)

5. A. Mestron, S.M. Webb, R. Astorga, P. Benito, M. Catala, S. Gaztambide, J. Gomez, I. Halperin, T.M. Morante, B. Moreno, G. Obiols, P. de Pablos, C. Paramo, A. Pico, E. Torres, C. Varela, J. A. Vazquez, J. Zamora, M. Albareda, M. Gilabert, Epidemiology, clinical characteristics, outcome, morbidity and mortality in acromegaly based on the Spanish Acromegaly Registry (Registro Español de Acromegalia, REA). Eur J Endocrinol. 151, 439-46 (2004)

6. S. Fieffe, I. Morange, P. Petrossians, P. Chanson, V. Rohmer, C. Cortet, F. Borson-Chazot, T. Brue, B. Delemer,, Diabetes in acromegaly, prevalence, risk factors, and evolution: data from the French Acromegaly Registry. Eur J Endocrinol. 164, 877-84 (2011)

7. L.A. Portocarrero-Ortiz, A. Vergara-Lopez, M. Vidrio-Velazquez, A.M. Uribe-Diaz, A. García-Dominguez, A.A. Reza-Albarrán, D. Cuevas-Ramos, V. Melgar, J. Talavera, A. de Jesus Rivera-Hernandez, C.V. Valencia-Méndez, M. Mercado; Mexican Acromegaly Registry Group, The Mexican acromegaly registry: clinical and biochemical characteristics at diagnosis and therapeutic outcomes. J Clin Endocrinol Metab. 101, 3997-4004 (2016)

8. P. Petrossians, A.F. Daly, E. Natchev, L. Maione, K. Blijdorp, M. Sahnoun-Fathallah, R. Auriemma, A.M. Diallo, A.L. Hulting, D. Ferone, V. Hana, S. Filipponi, C. Sievers, C. Nogueira, C. Fajardo-Montañana, D. Carvalho, V. Hana, G.K. Stalla, M.J. Jaffrain-Réa, B. Delemer, A. Colao, T. Brue, S.J.C.M.M. Neggers, S. Zacharieva, P. Chanson, A. Beckers, P. Petrossians, A.F. Daly, E. Natchev, Acromegaly at diagnosis in 3173 patients from the Liège Acromegaly Survey (LAS) Database. Endocr. Relat. Cancer 24, 505-18 (2017)

9. M. Arosio, G. Reimondo, E. Malchiodi, P. Berchialla, A. Borraccino, L. De Marinis, R. Pivonello, S. Grottoli, M. Losa, S. Cannavò, F. Minuto, M. Montini, M. Bondanelli, E. De Menis, C. Martini, G. Angeletti, A. Velardo, A. Peri, M. Faustini-Fustini, P. Tita, F. Pigliaru, G. Borretta, C. Scaroni, N. Bazzoni, A. Bianchi, M. Appetecchia, F. Cavagnini, G. Lombardi, E. Ghigo, P. BeckPeccoz, A. Colao, M. Terzolo,Italian Study Group of Acromegaly, Predictors of morbidity and mortality in acromegaly: an Italian survey. Eur J Endocrinol. 167, 189-98 (2012)

10. Espinosa-de-los-Monteros A.L., González B., Vargas G., Sosa E., Mercado M. Clinical and biochemical characteristics of acromegalic patients with different abnormalities in glucose metabolism. Pituitary. (2011). https://doi.org/10.1007/s11102-010-0284-x

11. T. Feola, A. Cozzolino, I. Simonelli, E. Sbardella, C. Pozza, E. Giannetta, D. Gianfrilli, P. Pasqualetti, A. Lenzi, A.M. Isidori, Glucose metabolism in acromegaly: a meta-analysis of prospective interventional studies. J Clin Endocrinol Metab. 104, 2892-902 (2019)

12. C. Urbani, C. Sardella, A. Calevro, G. Rossi, I. Scattina, M. Lombardi, I. Lupi, L. Manetti, E. Martino, F. Bogazzi, Effects of medical therapies for acromegaly on glucose metabolism. Eur $\mathbf{J}$ Endocrinol. 169, 99-108 (2013)

13. A. Colao, M.D. Bronstein, P. Freda, F. Gu, C.-C. Shen, M. Gadelha, M. Fleseriu, A.J. van der Lely, A.J. Farrall, K. Hermosillo Reséndiz, M. Ruffin, Y. Chen, M. Sheppard,on behalf of the Pasireotide C2305 Study Group, Pasireotide versus octreotide in acromegaly: a head-to-head superiority study. J Clin Endocrinol Metab. 99(3), 791-799 (2014)

14. M.R. Gadelha, M.D. Bronstein, T. Brue, M. Coculescu, M. Fleseriu, M. Guitelman, V. Pronin, G. Raverot, I. Shimon, K.K. Lievre, J. Fleck, M. Aout, A.M. Pedroncelli, A. Colao,Pasireotide C2402 Study Group, Pasireotide versus continued treatment with octreotide or lanreotide in patients with inadequately controlled acromegaly (PAOLA): a randomised, phase 3 trial. Lancet Diabetes Endocrinol. 2, 875-84 (2014)

15. Petersenn, S., Schopohl, J., Barkan, A., Mohideenet, P., Colao, A., Abs, R., Buchelt, A., Ho, Y.Y., Hu, K., Farrall, A.J., Melmed, S., Biller, B.M.K. Pasireotide (SOM230) demonstrates efficacy and safety in patients with acromegaly: a randomized, multicenter, phase II trial. J Clin Endocrinol Metab. (2010). https://doi.org/10. 1210/jc.2009-2272

16. Colao, A., Auriemma, R.S., Lombardi, G., Pivonello, R. Resistance to somatostatin analogs in acromegaly. Endocr Rev. (2011). https://doi.org/10.1210/er.2010-0002

17. Gola, M., Bonadonna, S., Mazziotti, G., Amato, G., Giustina, A. Resistance to somatostatin analogs in acromegaly: an evolving concept? J Endocrinol Invest. (2006). https://doi.org/10.1007/ BF03349183

18. A. Giustina, P. Chanson, M.D. Bronstein, A. Klibanski, S. Lamberts, F.F. Casanueva, P. Trainer, E. Ghigo, K. Ho, S. Melmed, Acromegaly Consensus Group, A consensus on criteria for cure of acromegaly. J Clin Endocrinol Metab. 95(7), 3141-3148 (2010)

19. Giustina, A., Barkhoudarian, G., Beckers, A., Ben-Shlomo, A., Biermasz, N., Biller, B., Boguszewski, C., Bolanowski, M., Bollerslev, J., Bonert, V., Bronstein, M.D., Buchfelder, M., Casanueva, F., Chanson, P., Clemmons, D., Fleseriu, M., Formenti, A.M., Freda, P., Gadelha, M., Geer, E., Gurnell, M., Heaney, A.,.P., Ho, K.K.Y., Ioachimescu, A.G., Lamberts, S., Laws, E., Losa, M., Maffei, P., Mamelak, A., Mercado, M., Molitch, M., Mortini, P., Pereira, A.M., Petersenn, S., Post, K., Puig-Domingo, M., Salvatori, R., Samson, S.L., Shimon, I., Strasburger, C., Swearingen, B., Trainer, P., Vance, M.L., Wass, J., Wierman, M.E., Yuen, K.C.J., Zatelli, M.C., Melmed, S. Multidisciplinary management of acromegaly: a consensus. Rev Endocr Metab Disord. (2020). https://doi.org/10.1007/s11154020-09588-Z

20. American Diabetes Association. Classification and diagnosis of diabetes: standards of medical care in diabetes-2020. Diabetes Care. (2020). https://doi.org/10.2337/dc20-S002

21. Fleseriu, M., Biller, B.M.K., Freda, P.U., Gadelha, M.R., Giustina, A., Katznelson, L., Molitch, M.E., Samson, S.L., Strasburger, C.J., van der Lely, A.J., Melmed, S. A Pituitary Society update to acromegaly management guidelines. Pituitary. (2020). https://doi. org/10.1007/s11102-020-01091-7

22. Giustina, A., Barkan, A., Beckers, A., Biermasz, N., Biller, B.M. K., Boguszewski, C., Bolanowski, M., Bonert, V., Bronstein, M. D., Casanueva, F.F., Clemmons, D., Colao, A., Ferone, D., Fleseriu, M., Frara, S., Gadelha, M.R., Ghigo, E., Gurnell, M., Heaney, A.P., Ho, K., Ioachimescu, A., Katznelson, L., Kelestimur, F., Kopchick, J., Krsek, M., Lamberts, S., Losa, M., Luger, A., Maffei, P., Marazuela, M., Mazziotti, G., Mercado, M., Mortini, P., Neggers, S., Pereira, A.M., Petersenn, S., PuigDomingo, M., Salvatori, R., Shimon, I., Strasburger, C., Tsagarakis, S., van der Lely, A.J., Wass, J., Zatelli, M.C., Melmed, S. A consensus on the diagnosis and treatment of acromegaly comorbidities: an update. J Clin Endocrinol Metab. (2020). https://doi. org/10.1210/clinem/dgz096

23. Mazziotti, G., Floriani, I., Bonadonna, S., Torri, V., Chanson, P., Giustina, A. Effects of somatostatin analogs on glucose homeostasis: a metaanalysis of acromegaly studies. Clin Endocrinol Metab. (2009) https://doi.org/10.1210/jc.2008-2332

24. Schmid, H.A., Brue, T., Colao, A., Gadelha, M.R., Shimon, I., Kapur, K., Pedroncelli, A.M., Fleseriu, M. Effect of pasireotide on glucose- and growth hormone-related biomarkers in patients with inadequately controlled acromegaly. Endocrine. (2016). https:// doi.org/10.1007/s12020-016-0895-8

25. A. Luger, Hyperglycemia in pasireotide-treated patients with acromegaly and its treatment. Endocrine. 54, 0-1 (2016) 
26. Giustina, A. Acromegaly and vertebral fractures: facts and questions. Trends Endocrinol Metab. (2020). https://doi.org/10.1016/j. tem.2020.01.011

27. Chiloiro, S., Giampietro, A., Frara, S., Bima, C., Donfrancesco, F., Fleseriu, C.M., Pontecorvi, A., Giustina, A., Fleseriu, M., De Marinis, L., Bianchi A. Effects of pegvisomant and pasireotide LAR on vertebral fractures in acromegaly resistant to firstgeneration SRLs. J Clin Endocrinol Metab. (2020). https://doi.org/ 10.1210/clinem/dgz054

28. Chiloiro, S., Mazziotti, G., Giampietro, A., Bianchi, A., Frara, S., Mormando, M., Pontecorvi, A., Giustina, A., De Marinis, L. Effects of pegvisomant and somatostatin receptor ligands on incidence of vertebral fractures in patients with acromegaly. Pituitary. (2018). https://doi.org/10.1007/s11102-018-0873-7

29. S. Frara, F. Maffezzoni, G. Mazziotti, A. Giustina, Current and emerging aspects of diabetes mellitus in acromegaly. Trends Endocrinol Metab. 27, 470-83 (2016)

30. A. Vijayakumar, R. Novosyadlyy, Y.J. Wu, S. Yakar, D. LeRoith, Biological effects of growth hormone on carbohydrate and lipid metabolism. Growth Horm. IGF Res. 20, 1-7 (2010)

31. S. Karlander, M. Vranić, S. Efendić, Increased glucose turnover and glucose cycling in acromegalic patients with normal glucose tolerance. Diabetologia. 29, 778-83 (1986)

32. J.P. del Rincon, K. Iida, B.D. Gaylinn, C.E. McCurdy, J.W. Leitner, L.A. Barbour, J.J. Kopchick, J.E. Friedman, B. Draznin, M.O. Thorner, Growth hormone regulation of p85 expression and phosphoinositide 3-kinase activity in adipose tissue: mechanism for growth hormone-mediated insulin resistance. Diabetes. 56, 1638-46 (2007)

33. N. Møller, J.O.L. Jørgensen, Effects of growth hormone on glucose, lipid, and protein metabolism in human subjects. Endocr Rev. 30, 152-77 (2009)

34. J.H. Nielsen, S. Linde, B.S. Welinder, N. Billestrup, O.D. Madsen, Growth hormone is a growth factor for the differentiated pancreatic $\beta$-cell. Mol Endocrinol. 3, 165-73 (1989)

35. O. Alexopoulou, M. Bex, P. Kamenicky, A.B. Mvoula, P. Chanson, D. Maiter, Prevalence and risk factors of impaired glucose tolerance and diabetes mellitus at diagnosis of acromegaly: a study in 148 patients. Pituitary. 17, 81-89 (2014)

36. Vila, G., Jørgensen, J.O.L., Luger, A., Stalla, G.K. Insulin resistance in patients with acromegaly. Front Endocrinol. (2019). https://doi.org/10.3389/fendo.2019.00509

37. A. Giustina, J.D. Veldhuis, Pathophysiology of the neuroregulation of growth hormone secretion in experimental animals and the human. Endocr Rev. 19, 717-97 (1998)

38. G. Mazziotti, T. Porcelli, F. Bogazzi, G. Bugari, S. Cannavò, A. Colao, R. Cozzi, L. De Marinis, E. degli Uberti, S. Grottoli, F.
Minuto, M. Montini, M. Spinello, A. Giustina, Effects of highdose octreotide LAR on glucose metabolism in patients with acromegaly inadequately controlled by conventional somatostatin analog therapy. Eur J Endocrinol. 164(3), 341-7 (2011). https:// doi.org/10.1530/EJE-10-0811.

39. Chiloiro, S., Giampietro, A., Mirra, F., Donfrancesco, F., Tartaglione, T., Mattogno, P.P., Angelini, F., Lauretti, L., Gessi, M., Anile, C., Rindi, G., Giustina, A., Fleseriu, M., Pontecorvi, A., De Marinis, L., Bianchi, A. Pegvisomant and Pasireotide LAR as second line therapy in acromegaly: Clinical effectiveness and predictors of response. Eur J Endocrinol. (2020). https://doi.org/ 10.1530/EJE-20-0767

40. Coopmans, E.C., Korevaar, T.I.M., van Meyel, S.W.F., Daly, A. F., Chanson, P., Brue, T., Delemer, B., Hána, V., Colao, A., Carvalho, D., Jaffrain-Rea, M.L., Stalla, G.K., Fajardo-Montañana, C., Beckers, A., van der Lely, A.J., Petrossians, P., Neggers, S.J.C.M.M. Multivariable prediction model for biochemical response to first-generation somatostatin receptor ligands in acromegaly. J Clin Endocrinol Metab. (2020). https://doi.org/10. 1210/clinem/dgaa387

41. Chiloiro, S., Bima, C., Tartaglione, T., Giampietro, A., Gessi, M., Lauretti, L., Anile, C., Colosimo, C., Rindi, G., Pontecorvi, A., De Marinis, L., Bianchi, A. Pasireotide and pegvisomant combination treatment in acromegaly resistant to second-line therapies: a longitudinal study. J Clin Endocrinol Metab. (2019) https://doi. org/10.1210/jc.2019-00825.

42. Muhammad, A., Coopmans, E.C., Delhanty, P.J.D., Dallenga, A. H.G., Haitsma, I.K., Janssen, J.A.M.J.L., van der Lely, A.J., Neggers, S.J.C.M.M. Efficacy and safety of switching to pasireotide in acromegaly patients controlled with pegvisomant and somatostatin analogues: PAPE extension study. Eur J Endocrinol. (2018). https://doi.org/10.1530/EJE-18-0353

43. A. Giustina, G. Arnaldi, F. Bogazzi, S. Cannavò, A. Colao, L. De Marinis, E. De Menis, E. Degli Uberti, F. Giorgino, S. Grottoli, A. G. Lania, P. Maffei, R. Pivonello, E. Ghigo, Pegvisomant in acromegaly: an update. J Endocrinol Invest 40(6), 577-589 (2017). https://doi.org/10.1007/s40618-017-0614-1.

44. Ciresi, A., Radellini, S., Guarnotta, V., Giordano, C. Efficacy of combined treatment with pasireotide, pegvisomant and cabergoline in an acromegalic patient resistant to other treatments: a case report. BMC Endocr Disord. (2018). https://doi.org/10.1186/ s12902-018-0231-9

45. Melmed, S., Bronstein, M.D., Chanson, P., Klibanski, A., Casanueva, F.F., Wass, J.A.H., Strasburger, C.J., Luger, A., Clemmons, D.R., Giustina, A. A consensus statement on acromegaly therapeutic outcomes. Nat Rev Endocrinol. (2018). https://doi.org/ 10.1038/s41574-018-0058-5. 